OPEN ACCESS

Edited by:

Xiongwei Zhu,

Case Western Reserve University,

USA

Reviewed by:

Gopal Thinakaran,

University of Chicago, USA

Riqiang Yan,

Cleveland Clinic Lerner College

of Medicine, USA

${ }^{*}$ Correspondence:

Xin Wang

wangx@xmu.edu.cn

Received: 15 November 2016 Accepted: 29 November 2016 Published: 15 December 2016

Citation:

Zheng Q, Huang T, Zhang L, Zhou Y, Luo H, Xu H and Wang X (2016)

Dysregulation of Ubiquitin-Proteasome System in Neurodegenerative Diseases.

Front. Aging Neurosci. 8:303. doi: 10.3389/fnagi.2016.00303

\section{Dysregulation of Ubiquitin-Proteasome System in Neurodegenerative Diseases}

\author{
Qiuyang Zheng ${ }^{1}$, Timothy Huang ${ }^{2}$, Lishan Zhang ${ }^{1}$, Ying Zhou ${ }^{1}$, Hong Luo ${ }^{1}$, Huaxi Xu1,2 \\ and Xin Wang ${ }^{1 *}$
}

${ }^{1}$ Fujian Provincial Key Laboratory of Neurodegenerative Disease and Aging Research, Institute of Neuroscience, College of Medicine, Collaborative Innovation Center for Brain Science, Xiamen University, Xiamen, China, ${ }^{2}$ Neuroscience Initiative,

Sanford Burnham Prebys Medical Discovery Institute, La Jolla, CA, USA

The ubiquitin-proteasome system (UPS) is one of the major protein degradation pathways, where abnormal UPS function has been observed in cancer and neurological diseases. Many neurodegenerative diseases share a common pathological feature, namely intracellular ubiquitin-positive inclusions formed by aggregate-prone neurotoxic proteins. This suggests that dysfunction of the UPS in neurodegenerative diseases contributes to the accumulation of neurotoxic proteins and to instigate neurodegeneration. Here, we review recent findings describing various aspects of UPS dysregulation in neurodegenerative disorders such as Alzheimer's disease, Parkinson's disease, and Huntington's disease.

Keywords: ubiquitin, deubiquitinating enzyme, proteasome, Alzheimer's disease, Parkinson's disease, Huntington's disease

\section{ABNORMAL PROTEIN AGGREGATION IN NEURODEGENERATIVE DISEASES}

Many neurodegenerative diseases are associated with aggregate-prone neurotoxic proteins (aggresomes or inclusion bodies) that perturb cellular homeostasis and neuronal function (Popovic et al., 2014). These diseases are also categorically classed as proteinopathies, and comprise aggregation-prone components such as $\beta$-amyloid $(\mathrm{A} \beta)$ and tau in Alzheimer's disease (AD), $\alpha$-synuclein in Parkinson's disease (PD), and polyglutamine (polyQ) repeat diseases.

Alzheimer's disease is the most common form of progressive neurodegeneration and represents the main cause of senile dementia affecting about $10 \%$ of the population over the age of 65 and about $50 \%$ of the population over 85 . AD can be divided into two forms: familial $\mathrm{AD}$ and sporadic AD. Familial AD accounts for $5 \% \sim 10 \%$ of $\mathrm{AD}$ patients, where inherited autosomal dominant mutations in three genes have been considered as the primary causes of familial $\mathrm{AD}$ : these include mutations in the genes encoding $\beta$-amyloid precursor protein (APP) and presenilins (PS1 and PS2; Goate et al., 1991; Levy-Lahad et al., 1995; Sherrington et al., 1995). In addition, sporadic $\mathrm{AD}$ is associated with polymorphisms in the Apolipoprotein $\mathrm{E}$ (APOE) gene, where the epsilon four allele is a strong genetic risk factor for late-onset $\mathrm{AD}$ (Strittmatter et al., 1993; Bu, 2009; Fu et al., 2016). Accumulation and aggregation of neurotoxic proteins, such as $\beta$-amyloid $(\mathrm{A} \beta)$, hyperphosphorylated tau, ubiquitinated proteins, and other unfolded proteins in vulnerable brain regions such as the hippocampus and cortex in $\mathrm{AD}$ brain is central to disease pathogenesis (Selkoe, 2001). Two major pathological hallmarks in AD are extracellular amyloid plaques and intraneuronal neurofibrillary tangle (NFT; Zhang et al., 2011). NFTs are 
comprised of hyperphosphorylated microtubule-associated protein tau (Song et al., 2015; Yamada et al., 2015; Zempel and Mandelkow, 2015). Amyloid plaques are primarily comprised of $\mathrm{A} \beta$ which is derived from sequential cleavages of APP by $\beta$ - and $\gamma$-secretases (Zhang et al., 2011; Audrain et al., 2016). Cumulative evidence demonstrates that $\mathrm{A} \beta$ and tau are neurotoxic and can trigger a cascade of neurodegenerative processes ending in neuronal death, suggesting that overproduction/accumulation of $\mathrm{A} \beta$ and tau in vulnerable brain regions is the primary influence driving AD pathogenesis (Hardy and Selkoe, 2002; Gautam et al., 2015; Golovyashkina et al., 2015; Popugaeva et al., 2015).

Parkinson's disease is the second most common neurodegenerative disease, clinically characterized by motor abnormalities, including resting tremor, rigidity, hypokinesia, and postural instability (Dauer and Przedborski, 2003; More and Choi, 2015). The loss of dopaminergic neurons in the substantial nigra subregion of midbrain is the major cause of motor deficits (Chen et al., 2015). Major pathological features of PD include intraneuronal accumulation of Lewy bodies and dystrophic neurites (Lewy neurites), both of which comprise aggregated proteins, such as $\alpha$-synuclein, parkin, and ubiquitinated proteins (Hughes et al., 1992; Braak et al., 2003; Chiasserini et al., 2015; Xiang et al., 2015). Sporadic PD accounts for more than $90 \%$ of PD cases (Lang and Lozano, 1998), and only less than 10\% of familial PD cases are caused by monogenic mutations (Benitez et al., 2016). Mutations in the gene encoding $\alpha$-synuclein (Polymeropoulos et al., 1997; Helferich et al., 2015; Majbour et al., 2016; Schonherr et al., 2016) represent autosomal dominant familial PD, and mutations in genes encoding parkin (Kitada et al., 1998; Cha et al., 2015), UCHL1 (Leroy et al., 1998; Maraganore et al., 1999), DJ-1 (Bonifati et al., 2003), PINK1 (Valente et al., 2004), and LRRK2 (Zimprich et al., 2004; Saha et al., 2015) cause autosomal recessive familial PD.

Huntington's disease (HD) is an autosomal dominant progressive neurodegenerative disorder, clinically characterized by cognitive impairment, chorea and dystonia, bradykinesia, uncoordinated movement, mood disorder and other psychiatric symptoms, and behavioral difficulties (Huntington Study Group, 1996). As the most common of the polyQ disorders, HD is caused by expansion of a CAG repeat coding for polyQ in the N-terminus of the huntingtin protein (MacDonald et al., 1993; Evers et al., 2015; Nekrasov et al., 2016). There is a remarkable repeat length threshold effect, where polyQ chain expansion of 36 repeats triggers HD onset, whereas repeats of less than 35 are non-pathological (Chong et al., 1997). The polyQ expansion in the $\mathrm{N}$-terminus of huntingtin protein confers a gain-of-function phenotype, and is associated with significant neurotoxicity (Tallaksen-Greene et al., 2003).

In addition to huntingtin, expansion of polyQ-encoding CAG repeats in several genes have also been found in other polyQ repeat diseases, such as Ataxin-1 in spinocerebellar ataxia type 1 (SCA1), Ataxin-2 in SCA2, Atantin-3 in SCA3, $\alpha 1_{\mathrm{A}}$-voltagedependent calcium channel (CACNA1A) in SCA6, Ataxin-7 in SCA7, Atrophin-1 in dentatorubral-pallidoluysian atrophy (DRPLA), and androgen receptor in SBMA (Zoghbi and Orr, 2000; Del Cano-Espinel et al., 2015). All polyQ repeat disorders are dominant neurodegenerative diseases and are associated with pathological intracellular inclusion bodies in the affected brain regions (Ross et al., 1997; Zoghbi and Orr, 2000).

\section{UBIQUITIN-PROTEASOME SYSTEM}

Ubiquitin is an evolutionarily conserved 76-amino acid moiety covalently tandemly linked to target protein components for degradation by the ubiquitin-proteasome system (UPS), and is required for degradation of about $80 \%$ intracellular proteins in eukaryotes (Pickart, 2001). The presence of ubiquitin in intracellular inclusions has been found in various neurodegenerative diseases, for example, amyloid plaques and NFT in AD, Lewy bodies in PD, and intranuclear inclusions in polyQ disorders (Todi and Paulson, 2011).

Protein ubiquitination occurs through the coordinated activity of several enzymes, including an ubiquitin activating enzyme (E1 ligase), conjugating enzyme (E2 ligase), and E3 ligase. Initially, a single ubiquitin moiety is attached to an active-site Cysteine residue within the E1 ligase through a thioester bond in an ATP dependent manner. The activated ubiquitin is then transferred to an ubiquitin conjugating enzyme-E2 ligase. Finally, the E2 ligase will cooperatively transfer the ubiquitin chain with a specified E3 ligase to a particular substrate, whereby the $26 \mathrm{~S}$ proteasome will target the polyubiquitinated protein for degradation (Figure 1).

Ubiquitin E3 ligases determine the specificity of ubiquitination process. E3 ligases are grouped into three classes according to their unique domains, including Really Interesting New Gene (RING) or U-box domain-containing E3 ligases, Homologous to E6AP C-terminus (HECT) domain-containing E3 ligases, and RING-between-RING (RBR) domain-containing E3 ligases (Atkin and Paulson, 2014; Morreale and Walden, 2016). RING E3 ligases catalyze the transfer of ubiquitin directly from E2 ligases to the substrates by binding both of them. Whereas HECT E3 ligases comprise a conserved Cysteine residue as an ubiquitin acceptor, where the activated ubiquitin is initially transferred from the E2 ligases to HECT E3 ligases prior to E3-mediated substrate conjugation (Ravid and Hochstrasser, 2008). Unlike RING E3 ligases, RBR E3 ligases contain two RING domains (RING1 and RING2) separated by an in-between-RING (IBR) domain. Functionally, RBR E3 ligases are similar with HECT E3 ligases, both catalyze ubiquitin first transfer from E2 ligases to a catalytic Cysteine residue on E3 ligases then from the E3 ligases to the substrates (Spratt et al., 2014) (Figure 1).

The fate of an ubiquitin-linked protein is dependent on Lysine chain-specific polyubiquitination (Grabbe et al., 2011; Kulathu and Komander, 2012; Rieser et al., 2013). For example, Lys48-linked polyubiquitin chains usually target proteins for degradation (Husnjak et al., 2008), whereas Lys63-linked polyubiquitination is involved in regulation of NFKB signaling (Laplantine et al., 2009), Lys27-linked polyubiquitin chains are important for mitophagy (Geisler et al., 2010), and Lys11-linked polyubiquitination is implicated in cell cycle regulation (Bremm and Komander, 2011). Therefore, ubiquitination is not only important for protein degradation, but is also implicated in non-proteolytic functions, such as endocytosis, protein-protein interaction, intracellular trafficking, inflammatory signaling, 


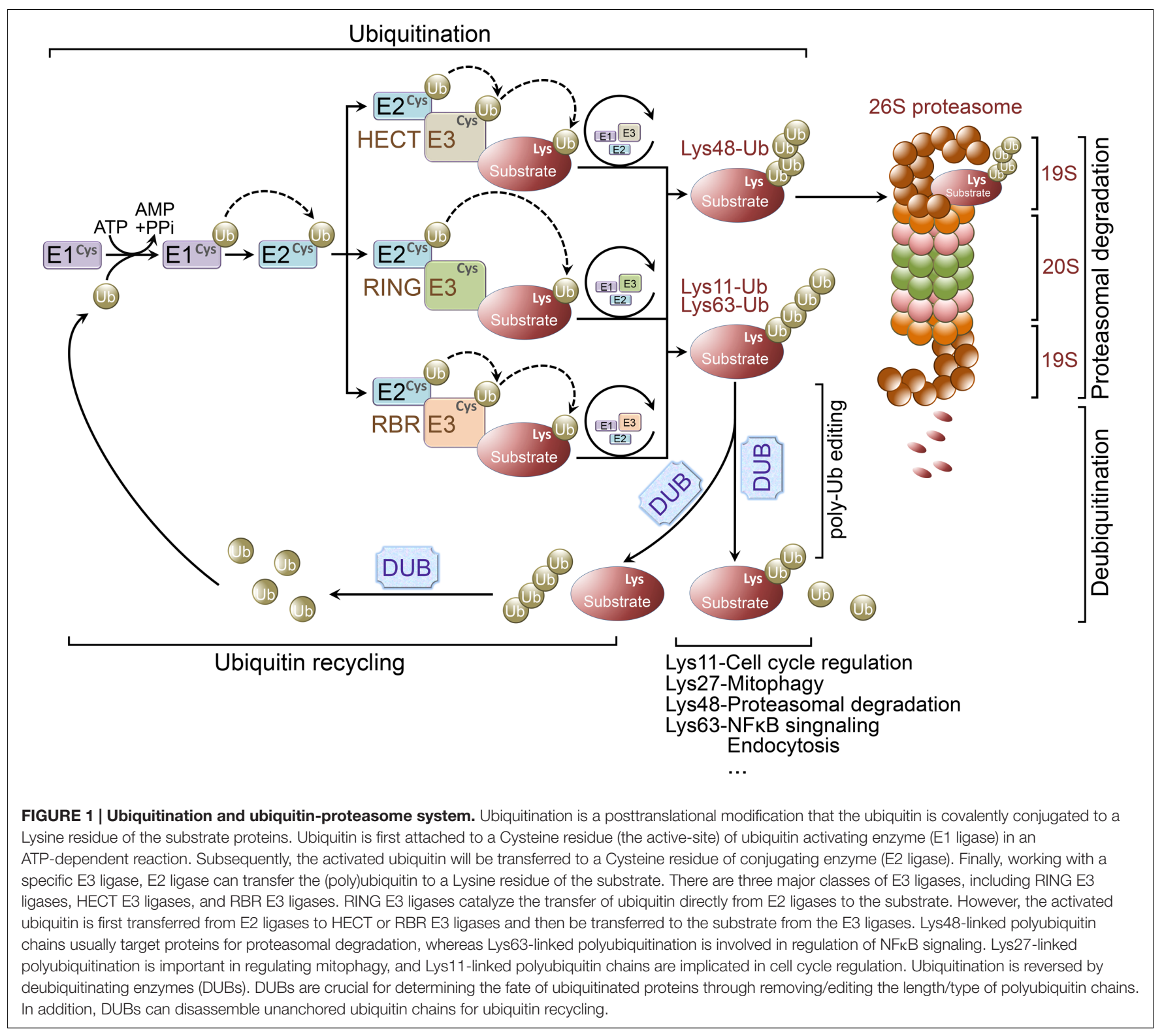

autophagy, and DNA repair (Grabbe et al., 2011; Kulathu and Komander, 2012; Rieser et al., 2013).

The UPS is involved in protein quality control and removal of misfolded and aggregated proteins, and dysfunction of the UPS is implicated in the pathogenesis of neurodegenerative diseases (Popovic et al., 2014).

\section{DEUBIQUITINATING ENZYMES}

The process of ubiquitination is reversible and the reverse process is called deubiquitination which is accomplished by deubiquitinating enzymes (DUBs; Rubinsztein, 2006; ReyesTurcu et al., 2009; Popovic et al., 2014). Increasing evidence indicates the importance of DUBs in regulating UPS function, including proofreading ubiquitin-protein conjugates, removing ubiquitin from conjugated proteins as key examples (Amerik and Hochstrasser, 2004) (Figure 1). Pivotal roles for DUBs have been demonstrated in maintaining neuronal functions and regulating the pathogenesis of various neurodegenerative diseases (Rubinsztein, 2006; Todi and Paulson, 2011; Popovic et al., 2014).

More than 100 DUBs have been identified (Popovic et al., 2014), and can be subdivided into five subfamilies. DUBs can be further categorized into two classes, the Cysteine proteases and the zinc-dependent metalloproteases (Todi and Paulson, 2011). Cysteine protease-associated DUBs include the ubiquitin carboxyl-terminal hydrolases (UCHs), ubiquitin specific proteases (USPs), Machado Joseph Diseases (MJD) proteases, and ovarian tumor (OTU) protease. Metalloprotease DUBs comprise the JAB1/MPN/Mov34 metalloenzyme (JAMM) subfamily. 
UCHL1, a member of the UCH subfamily, is one of the most abundant proteins in the brain. UCHL1 is known to interact with and stabilize monomeric ubiquitin, and facilitates the E3 ligase activity in its dimeric form (Doran et al., 1983; Wilkinson et al., 1989). An Aplysia UCHL1 ortholog, ubiquitin carboxylterminal hydrolase (AP-Uch) has been found to be important in maintaining synaptic function (Hegde et al., 1997). Inhibiting the expression or function of AP-Uch blocks induction of longterm facilitation, which is thought to be the molecular basis for learning and memory (Hegde et al., 1997). Mammalian UCHL1 is required for normal synaptic structure and function in hippocampal neurons (Cartier et al., 2009). Activation of NMDA receptor upregulates UCHL1 activity and the levels of free ubiquitin monomers. Inhibition of UCHL1 disrupts distribution of synaptic proteins, increases dendritic spine size and reduces spine density. However, restoration of ubiquitin in UCHL1-inhibited neurons rescues impaired synaptic structure (Cartier et al., 2009). UCHL1 is also essential for normal structure and function of neuromuscular junctions (NMJs), reduction of synaptic vesicles and accumulation of tubulovesicular structures at the presynaptic nerve terminals have been observed in Uchl1 knockout mice (Chen et al., 2010). UCHL3, a homolog of UCHL1, is involved in spatial and working memory (Wood et al., 2005).

$19 S$ proteasome-associated DUBs comprise three members: USP14, UCH37, and RPN11, which show differences in ubiquitin chains removals and consequent protein degradation (Lee et al., 2011). It has been reported that both USP14 and UCH37 prevent substrate degradation by removing ubiquitin chains and promoting proteasomal substrate dissociation. In contrast, RPN11 cleaves at the base of the ubiquitin-linked substrates and promotes substrate degradation (Lee et al., 2011). USP14 is essential for synaptic development and normal function of NMJs (Chen et al., 2009), which is mediated through ubiquitination and activation of c-Jun N-terminal kinase signaling (Vaden et al., 2015). Pharmacological inhibition of USP14 enhances proteasomal degradation of several neurotoxic proteins, including tau, TDP14, and Ataxin-3 (Lee et al., 2010). Usp14-deficient mice display motor neuron deficits and developmental NMJ defects (Chen et al., 2009). USP16, a chromosome 21-encoded gene, is involved in chromatin remodeling and cell cycle progression through regulated ubiquitination of histone H2A (Joo et al., 2007). USP16 interacts with HERC2 and modulates the ubiquitination in DNA repair machinery components (Zhang et al., 2014). USP16 is upregulated in Down's syndrome (DS) cells due to extrachromosomal triplication in trisomy 21, downregulation of USP16 partially restores the impaired proliferation in DS somatic stem cells (Adorno et al., 2013). It has been reported that USP16 acts as a $\mathrm{H} 2 \mathrm{~A}$ DUB and regulates hematopoiesis and hematopoietic stem cell function (Gu et al., 2016). Moreover, USP16 is required for embryonic stem cell differentiation, where USP16 deficiency leads to embryonic lethality in mouse deletion models (Yang et al., 2014).

The gene encoding USP25 also resides on human chromosome 21 (Valero et al., 1999), USP25 is involved in protein degradation by the $26 \mathrm{~S}$ proteasome (Valero et al., 1999). USP25 is also implicated in inflammation, and it has been found to facilitate removal of Lys63-linked ubiquitin chains from tumor necrosis factor-receptor associated factor 5/6 (TRAF5/6), Usp25-deficient mice show higher sensitivity to IL-17 dependent inflammation and autoimmunity (Zhong et al., 2012).

\section{DYSREGULATION OF UBIQUITINATION IN NEURODEGENERATIVE DISEASES}

Accumulating evidence indicates that dysfunction of the UPS is a key factor to initiate and aggravate the pathogenesis of neurodegenerative diseases. We will focus on the dysregulation of ubiquitination and proteasomal degradation in neurodegenerative pathology in $\mathrm{AD}, \mathrm{PD}$, and $\mathrm{HD}$ (Table 1).

\section{Dysregulation of the UPS in Alzheimer's Disease}

The presence of ubiquitin in NFTs and amyloid plaques in AD brain has been described as early as 1987 (Cole and Timiras, 1987; Mori et al., 1987; Perry et al., 1987). Ubiquitintargeted proteasomal activity declines with age Tg2576 AD mouse model brain, and $\mathrm{A} \beta$ treatment markedly attenuates proteasomal activity in cultured neurons (Oh et al., 2005). A $\beta$ induced UPS dysfunction contributes to the accumulation of reticulon 3 (RTN3) in dystrophic neurites, and the presence of dystrophic neurites and clustering of tubular endoplasmic reticulum has been observed in RTN3 transgenic mouse brain (Hu et al., 2007; Sharoar et al., 2016). Interestingly, intracellular $\mathrm{A} \beta$ accumulation and impaired proteasome function can be reversed by the ubiquitin E3 ligase parkin (Rosen et al., 2010). Parkin expression is downregulated in $\mathrm{AD}$ brains, and reduced parkin expression may contribute to the accumulation of intracellular $\mathrm{A} \beta$. Moreover, parkin expression results in $A \beta$ reduction which can be dampened by proteasome inhibitors (Rosen et al., 2010). In addition, overexpression of parkin in APP/PS1 mouse models restores impaired longterm potentiation (LTP) and rescues behavioral abnormalities by reducing $A \beta$ load and neuroinflammation (Hong et al., 2014).

UCHL1 has been observed in ubiquitin-enriched inclusion bodies in AD brains (Lowe et al., 1990). In addition, decreased soluble UCHL1 protein levels was detected in the brains of postmortem AD patients and APP/PS1 mouse models (Choi et al., 2004; Gong et al., 2006), and soluble UCHL1 is inversely proportional to the number of NFTs in AD brains (Choi et al., 2004). Upregulation of UCHL1 improves contextual learning and restores synaptic functions in APP/PS1 mouse models, where rescue effects are dependent on enzymatic UCHL1 activity (Gong et al., 2006). Moreover, overexpression of UCHL1 reduces the levels of $\beta$-secretase BACE1, and consequent BACE1 cleavage products (APP C-terminal fragment C99 and $A \beta)$. Depletion of UCHL1 increases the levels of BACE1, C99, and A $\beta$ in the Uchl1-null gad mice (Zhang et al., 2012). 
TABLE 1 | Ubiquitin-proteasome system is implicated in neurodegenerative diseases pathogenesis.

\begin{tabular}{|c|c|c|c|c|}
\hline Disease & Protein & Disease Relevance & Pathogenesis & Reference \\
\hline$A D$ & Parkin (E3 ligase) & Decreased in AD & $\begin{array}{l}\text { Parkin overexpression reduces } A \beta \text { and restores } \\
\text { impaired LTP and behavioral abnormalities of } \\
\text { APP/PS1 mouse model. }\end{array}$ & Rosen et al., 2010; Hong et al., 2014 \\
\hline$A D$ & UCHL1 (DUB) & Decreased in AD & $\begin{array}{l}\text { UCHL1 overexpression improves contextual } \\
\text { memory and restores synaptic functions of } \\
\text { APP/PS1 mouse model. }\end{array}$ & Choi et al., 2004; Gong et al., 2006 \\
\hline$A D$ & HRD1 (E3 ligase) & Decreased in AD & $\begin{array}{l}\text { HRD1 reduces A } \beta \text { generation through interacting } \\
\text { with APP and facilitating APP ubiquitination and } \\
\text { proteasomal degradation. }\end{array}$ & Kaneko et al., 2010 \\
\hline$A D$ & CHIP (E3 ligase) & Upregulated in $\mathrm{AD}$ & $\begin{array}{l}\text { CHIP ubiquitinates phosphorylated tau. Deletion } \\
\text { of } \mathrm{CHIP} \text { leads to the accumulation of } \\
\text { non-aggregated, hyperphosphorylated, as well as } \\
\text { caspase-3-cleaved tau species. } \\
\text { Overexpression of CHIP and Hsp } 70 / 90 \text { decreases } \\
\text { the steady-state A } \beta \text { levels and promotes A } \beta \\
\text { degradation. }\end{array}$ & $\begin{array}{l}\text { Petrucelli et al., 2004; Shimura et al., 2004; } \\
\text { Dickey et al., 2006, 2007; Kumar et al., } 2007\end{array}$ \\
\hline PD & Parkin (E3 ligase) & $\begin{array}{l}\text { Decreased in PD with } \\
\text { loss-of-function mutations }\end{array}$ & $\begin{array}{l}\text { More than } 100 \text { different PARK2 (encoding parkin) } \\
\text { mutations have been found in PD patients, } \\
\text { including missense, truncation, copy number } \\
\text { variations, deletions, and insertions. } \\
\text { Loss-of-function mutations in parkin impair its E3 } \\
\text { ligase activity and lead to the accumulation of } \\
\alpha \text {-synuclein and the formation of Lewy bodies. }\end{array}$ & $\begin{array}{l}\text { Shimura et al., 2001; Lesage and Brice, 2009; } \\
\text { Lu et al., 2009; Chung et al., } 2013\end{array}$ \\
\hline PD & UCHL1 (DUB) & $\begin{array}{l}\text { Mutation on } 193 \mathrm{M} \text { and } \\
\text { S18Y. }\end{array}$ & $\begin{array}{l}\text { UCHL1 }{ }^{193 \mathrm{M}} \text { mutation promotes its dimerization } \\
\text { and inhibits the proteasomal degradation of } \\
\alpha \text {-synuclein through the Lys63-linked } \\
\text { polyubiquitination of } \alpha \text {-synuclein. }\end{array}$ & $\begin{array}{l}\text { Leroy et al., 1998; Liu et al., 2002; Maraganore } \\
\text { et al., 2004; Setsuie et al., } 2007\end{array}$ \\
\hline PD & CHIP (E3 ligase) & NA & $\begin{array}{l}\text { CHIP can enhance parkin's E3 ligase activity. } \\
\text { Moreover, CHIP ubiquitinates LRRK2 and } \\
\alpha \text {-synuclein and promotes their degradation. }\end{array}$ & $\begin{array}{l}\text { Imai et al., 2002; Ko et al., 2009; Kalia et al., } \\
2011\end{array}$ \\
\hline PD & TRAF6 (E3 ligase) & Upregulated in PD & $\begin{array}{l}\text { TRAF6 promotes Lys6-, Lys27-, and Lys29-linked } \\
\text { ubiquitination of DJ-1 and } \alpha \text {-synuclein. TRAF6 } \\
\text { induces Lys63-linked ubiquitination of PINK1, and } \\
\text { stabilizes PINK1 on the depolarized mitochondria. }\end{array}$ & $\begin{array}{l}\text { Zucchelli et al., 2010; Chung et al., 2013; } \\
\text { Murata et al., } 2013\end{array}$ \\
\hline HD & CHIP (E3 ligase) & NA & $\begin{array}{l}\text { CHIP suppresses aggregation and toxicity of } \\
\text { polyQ-huntingtin. Knockdown of CHIP in HD } \\
\text { transgenic mice aggravates disease pathology. }\end{array}$ & Miller et al., 2005 \\
\hline SCA3 & Ataxin-3 (E3 ligase) & $\begin{array}{l}\text { Gain-of-function mutation } \\
\text { with polyQ expansion }\end{array}$ & $\begin{array}{l}\text { Ataxin-3 overexpression protects Drosophila from } \\
\text { polyQ-huntingtin-induced neurodegeneration. } \\
\text { MJD-linked Ataxin-3 mutations promote } \\
\text { ubiquitination and autophagic degradation of } \\
\text { parkin. }\end{array}$ & Warrick et al., 2005; Durcan et al., 2011 \\
\hline
\end{tabular}

A direct interaction between APP and ubiquitin ligases also contributes to amyloid pathology. HRD1, an endoplasmic reticulum-associated degradation (ERAD) ubiquitin E3 ligase, is reduced in $\mathrm{AD}$ brains (Kaneko et al., 2010). HRD1 interacts with APP through its Proline-rich region, and this interaction reduces $A \beta$ generation through promoting APP ubiquitination and degradation (Kaneko et al., 2010). In addition, APP can bind to ubiquitin E3 ligases Stub1 and CRL4 ${ }^{\text {CRBN }}$ through the APP cytosolic region (ACR; Del Prete et al., 2016). ACR promotes the ubiquitination of several presynaptic proteins and regulates neurotransmitter release (Del Prete et al., 2016).

Polyubiquitinated tau has also been found in the brains of AD patients (Perry et al., 1987), where ubiquitin conjugation usually occurs at Lys254, Lys311, and Lys353 within the tau microtubule-binding domain (Cripps et al., 2006). In AD brains, accumulation of hyperphosphorylated, ubiquitinated tau protein has been found at both presynaptic and postsynaptic terminals, which is associated with dysfunction of the UPS (Tai et al., 2012). Recently, Myeku et al. reported that tau can induce dysfunction of the $26 \mathrm{~S}$ proteasome which can be prevented by activating cAMP-PKA signaling. Protective effects derived from cAMPPKA signaling are mediated through phosphorylation of the $26 \mathrm{~S}$ proteasomal subunit (Myeku et al., 2016). Han et al. directly delivered purified proteasomes into cells through mesoporous silica nanoparticle-mediated endocytosis, and they found that extraproteasomal transfer reduces tau aggregates and promotes cell survival against tau-induced proteotoxic stress (Han et al., 2014). C-terminus of Hsp70-interacting protein (CHIP), an ubiquitin $\mathrm{E} 3$ ligase, is also implicated in $\mathrm{AD}$ pathogenesis. It has 
been found that both CHIP and Hsp70 are upregulated in the brains of AD patients (Sahara et al., 2005). CHIP and its binding protein Hsp70 can induce the ubiquitination and degradation of phosphorylated tau (Petrucelli et al., 2004; Shimura et al., 2004), deletion of CHIP leads to the accumulation of nonaggregated, hyperphosphorylated, as well as caspase-3-cleaved tau (Dickey et al., 2006). Moreover, inhibition of Hsp90 reduces hyperphosphorylated tau through an interaction with CHIP (Dickey et al., 2007). In addition, overexpression of CHIP and Hsp70/90 decreases steady-state $A \beta$ levels and promotes $A \beta$ degradation (Kumar et al., 2007).

\section{Dysregulation of UPS in Parkinson's Disease}

The presence of ubiquitin-immunopositive Lewy bodies in the brains of PD patients has been observed about 30 years ago (Kuzuhara et al., 1988). Impaired proteasomal function in the substantia nigra of PD brains was later observed (McNaught and Jenner, 2001). Importantly, genetic evidence reveals a clear involvement of UPS dysfunction in PD pathogenesis: familial $\mathrm{PD}$-associated genetic variations have been identified on PARK2 (Kitada et al., 1998) and UCHL1 (Leroy et al., 1998; Maraganore et al., 1999), which encode the ubiquitin E3 ligase parkin and deubiquitinating enzyme UCHL1, respectively. Recessive earlyonset familial PD can also be caused by mutations in genes encoding DJ-1 (Abou-Sleiman et al., 2003; Bonifati et al., 2003) and PINK1 (Valente et al., 2004), presumably through a loss-offunction mechanism.

An interaction between parkin and its substrate $\alpha$-synuclein is a crucial regulatory component of dopaminergic neuron degeneration, loss-of-function mutations in PARK2 usually cause early-onset autosomal recessive PD (Kitada et al., 1998), whereas disease-associated mutations in $\alpha$-synuclein are usually associated with autosomal dominant PD (Polymeropoulos et al., 1997). Mutant parkin fails to interact with $\alpha$-synuclein, leads to the accumulation of $\alpha$-synuclein and the formation of Lewy bodies (Shimura et al., 2001). Transgenic mice carrying mutant parkin ${ }^{\mathrm{Q} 11 \mathrm{X}}$ develop progressive hypokinetic motor deficits, accumulation of $\alpha$-synuclein and age-dependent loss of dopaminergic neurons in the substantia nigra and striatum ( $\mathrm{Lu}$ et al., 2009).

Parkin is an E3 ligase mediating multiple forms of ubiquitination, including monoubiquitination, Lys48- and Lys63-linked polyubiquitination (Moore, 2006). In addition, parkin can form an E3 ligase complex with PINK1 and DJ-1 to promote unfolded protein degradation (Xiong et al., 2009): PD mutations in each component impair E3 ligase activity (Xiong et al., 2009). CHIP can promote parkin-mediated ubiquitination of Pael receptor and inhibit the Pael receptor-induced cell death (Imai et al., 2002). In addition, CHIP ubiquitinates and facilitates proteasomal degradation of LRRK2, where knockdown of CHIP exacerbates neurotoxicity mediated by mutant LRRK2 (Ko et al., 2009). CHIP can ubiquitinate $\alpha$-synuclein and reduce toxic $\alpha$-synuclein oligomers (Kalia et al., 2011). TRAF6 is upregulated in the brains of PD patients (Chung et al., 2013), and TRAF6 promotes Lys6-, Lys27-, and Lys29-linked ubiquitination of
DJ-1 and $\alpha$-synuclein. This interaction may cause aggregation of insoluble and polyubiquitinated mutant DJ-1 proteins (Zucchelli et al., 2010). Moreover, TRAF6 ubiquitinates PINK1 at Lys433 residue as a poly-Lys63 conjugated form which stabilizes PINK1 in depolarized mitochondria. Down-regulation of TRAF6 disrupts PINK1 localization, thereby causing mitochondria damage through parkin recruitment (Murata et al., 2013). Mutations in UCHL1 have been reported in rare cases of early-onset familial PD (Leroy et al., 1998; Maraganore et al., 1999). Most notably, the UCHL1 ${ }^{193 M}$ PD variant shows reduced deubiquitinating activity (Leroy et al., 1998). Ubiquitin-positive inclusion bodies and the loss of dopaminergic neurons have been observed in the substantia nigra of $\mathrm{UCHL}^{\mathrm{I} 93 \mathrm{M}}$ transgenic mouse brains (Setsuie et al., 2007). In addition, UCHL1 ${ }^{193 \mathrm{M}}$ mutation promotes dimerization and Lys63-linked polyubiquitination of $\alpha$-synuclein. Lys63-linked polyubiquitination may aggravate PD pathology by inhibiting proteasomal degradation of $\alpha$-synuclein (Liu et al., 2002).

\section{Dysregulation of UPS in Huntington's Disease}

HD patients manifest polyQ repeats of over 40 residues within the N-terminus of huntingtin protein. Ubiquitin-linked mutant huntingtin has been found in neuronal intranuclear inclusions and dystrophic neurites in the cortex and striatum of HD patients (Difiglia et al., 1997). However, it seems that eukaryotic proteasomes fail to cleave and eliminate pathogenic protein species with repeats greater than $25 \mathrm{Q}$ residues; this results in accumulation and aggregation of huntingtin protein in the neuronal nucleus (Venkatraman et al., 2004). However, it has been reported that a selective histone deacetylase (HDAC) inhibitor $4 \mathrm{~b}$ ameliorates cognitive impairment in N171-82Q HD mouse model by preventing formation of nuclear huntingtin aggregates. Mechanistically, HDAC inhibition upregulates expression of multiple genes that are fundamental to protein phosphorylation and ubiquitination, including $U b e 2 K$, Ubqln, Ube2e3, Usp28, Sumo2, as well as the genes encoding components of the inhibitor of $\kappa \mathrm{B}$ kinase (IKK) complex (Jia et al., 2012). It has been reported that CHIP suppresses polyQ aggregation and toxicity, and knockdown of CHIP in HD transgenic mice aggravated disease pathology (Miller et al., 2005).

Spinocerebellar ataxia type 3 (SCA3) is another polyQ repeat disease, which is caused by a polyQ-encoding CAG repeat expansion in the gene encoding Ataxin-3 (Kawaguchi et al., 1994). SCA3 is characterized by progressive ataxia with degeneration in the cerebellum, brain stem, substantia nigra, and globus pallidus interna. Clinical symptoms of SCA3 include impaired eye movement, speech and swallowing defects (Todi and Paulson, 2011). Ataxin-3 is a DUB from MJD subfamily of proteases which contain an ubiquitin interacting motif flanking the polyQ domain. Ataxin-3 preferentially cleaves Lys 63 linkages in polyubiquitinated chains containing both Lys48 and Lys63 linkages (Winborn et al., 2008). Overexpression of normal human Ataxin-3 can protect Drosophila from polyQ-huntingtininduced neurodegeneration (Warrick et al., 2005). Unlike wildtype Ataxin-3, MJD-linked mutant Ataxin-3 can promote 
ubiquitination and autophagic degradation of parkin probably through regulating the levels of Lys27- and Lys29 ubiquitinlinked parkin (Durcan et al., 2011).

\section{CONCLUSION}

Although UPS-mediated protein degradation has been wellstudied in the last few decades, regulation of ubiquitination and proteasomal degradation in normal brain function and pathogenesis of neurodegenerative diseases remains largely unknown. The regulation of polyubiquitination processes may vary at different physiological and/or pathologic conditions. This review surveyed dysregulation of UPS in several major neurodegenerative diseases, more research is required to understand how the UPS is disrupted in neurodegenerative pathogenesis. By enriching our understanding of protein degradation, we can begin to formulate strategies to treat neurodegenerative diseases remediating aspects of UPS dysregulation.

\section{REFERENCES}

Abou-Sleiman, P. M., Healy, D. G., Quinn, N., Lees, A. J., and Wood, N. W. (2003). The role of pathogenic DJ-1 mutations in Parkinson's disease. Ann. Neurol. 54, 283-286. doi: 10.1002/ana.10675

Adorno, M., Sikandar, S., Mitra, S. S., Kuo, A., Nicolis Di Robilant, B., HaroAcosta, V., et al. (2013). Usp16 contributes to somatic stem-cell defects in Down's syndrome. Nature 501, 380-384. doi: 10.1038/nature12530

Amerik, A. Y., and Hochstrasser, M. (2004). Mechanism and function of deubiquitinating enzymes. Biochem. Biophys. Acta 1695, 189-207. doi: 10.1016/ j.bbamcr.2004.10.003

Atkin, G., and Paulson, H. (2014). Ubiquitin pathways in neurodegenerative disease. Front. Mol. Neurosci. 7:63. doi: 10.3389/fnmol.2014.00063

Audrain, M., Fol, R., Dutar, P., Potier, B., Billard, J. M., Flament, J., et al. (2016). Alzheimer's disease-like APP processing in wild-type mice identifies synaptic defects as initial steps of disease progression. Mol. Neurodegener. 11:5. doi: 10.1186/s13024-016-0070-y

Benitez, B. A., Davis, A. A., Jin, S. C., Ibanez, L., Ortega-Cubero, S., Pastor, P., et al. (2016). Resequencing analysis of five Mendelian genes and the top genes from genome-wide association studies in Parkinson's Disease. Mol. Neurodegener. 11:29. doi: 10.1186/s13024-016-0097-0

Bonifati, V., Rizzu, P., Van Baren, M. J., Schaap, O., Breedveld, G. J., Krieger, E., et al. (2003). Mutations in the DJ-1 gene associated with autosomal recessive early-onset parkinsonism. Science 299, 256-259. doi: 10.1126/science.1077209

Braak, H., Del Tredici, K., Rub, U., De Vos, R. A. I., Steur, E., and Braak, E. (2003). Staging of brain pathology related to sporadic Parkinson's disease. Neurobiol. Aging 24, 197-211. doi: 10.1016/s0197-4580(02)00065-9

Bremm, A., and Komander, D. (2011). Emerging roles for Lys11-linked polyubiquitin in cellular regulation. Trends Biochem. Sci. 36, 355-363. doi: 10.1016/j.tibs.2011.04.004

Bu, G. (2009). Apolipoprotein E and its receptors in Alzheimer's disease: pathways, pathogenesis and therapy. Nat. Rev. Neurosci. 10, 333-344. doi: 10.1038/ nrn2620

Cartier, A. E., Djakovic, S. N., Salehi, A., Wilson, S. M., Masliah, E., and Patrick, G. N. (2009). Regulation of synaptic structure by ubiquitin C-terminal hydrolase L1. J. Neurosci. 29, 7857-7868. doi: 10.1523/jneurosci.1817-09.2009

Cha, S. H., Choi, Y. R., Heo, C. H., Kang, S. J., Joe, E. H., Jou, I., et al. (2015). Loss of parkin promotes lipid rafts-dependent endocytosis through accumulating caveolin-1: implications for Parkinson's disease. Mol. Neurodegener. 10:63. doi: 10.1186/s13024-015-0060-5

Chen, F., Sugiura, Y., Myers, K. G., Liu, Y., and Lin, W. (2010). Ubiquitin carboxylterminal hydrolase L1 is required for maintaining the structure and function

\section{AUTHOR CONTRIBUTIONS}

QZ, LZ, and XW wrote the manuscript, TH, YZ, HL, and HX edited the manuscript. All authors read and approved the final manuscript.

\section{ACKNOWLEDGMENTS}

This work was supported in part by National Natural Science Foundation of China (81571176 to XW, 91332114 and U1405222 to HX), the Thousand Young Talents Program of China, the Fundamental Research Funds for the Chinese Central Universities (20720150061 to XW), US National Institutes of Health grants (R01 AG038710, R01 AG021173, R01 NS046673, R01 AG030197, and R01 AG044420 to HX) and grants from the Alzheimer's Association (to HX) and the Global Down Syndrome Foundation (DSADIIP-13-283543, to HX), BrightFocus Foundation (to HX), and Cure Alzheimer's Fund (to HX).

of the neuromuscular junction. Proc. Natl. Acad. Sci. U.S.A. 107, 1636-1641. doi: 10.1073/pnas.0911516107

Chen, P. C., Qin, L. N., Li, X. M., Walters, B. J., Wilson, J. A., Mei, L., et al. (2009). The proteasome-associated deubiquitinating enzyme Usp14 is essential for the maintenance of synaptic ubiquitin levels and the development of neuromuscular junctions. J. Neurosci. 29, 10909-10919. doi: 10.1523/jneurosci. 2635-09.2009

Chen, Y., Zhang, D. Q., Liao, Z., Wang, B., Gong, S., Wang, C., et al. (2015). Anti-oxidant polydatin (piceid) protects against substantia nigral motor degeneration in multiple rodent models of Parkinson's disease. Mol. Neurodegener. 10:4. doi: 10.1186/1750-1326-10-4

Chiasserini, D., Paciotti, S., Eusebi, P., Persichetti, E., Tasegian, A., KurzawaAkanbi, M., et al. (2015). Selective loss of glucocerebrosidase activity in sporadic Parkinson's disease and dementia with Lewy bodies. Mol. Neurodegener. 10:15. doi: 10.1186/s13024-015-0010-2

Choi, J., Levey, A. I., Weintraub, S. T., Rees, H. D., Gearing, M., Chin, L. S., et al. (2004). Oxidative modifications and down-regulation of ubiquitin carboxylterminal hydrolase L1 associated with idiopathic Parkinson's and Alzheimer's diseases. J. Biol. Chem. 279, 13256-13264. doi: 10.1074/jbc.M314124200

Chong, S. S., Almqvist, E., Telenius, H., Latray, L., Nichol, K., Bourdelat-Parks, B., et al. (1997). Contribution of DNA sequence and CAG size to mutation frequencies of intermediate alleles for Huntington disease: evidence from single sperm analyses. Hum. Mol. Genet. 6, 301-309. doi: 10.1093/hmg/6.2.301

Chung, J. Y., Park, H. R., Lee, S. J., Lee, S. H., Kim, J. S., Jung, Y. S., et al. (2013). Elevated TRAF2/6 expression in Parkinson's disease is caused by the loss of Parkin E3 ligase activity. Lab. Invest. 93, 663-676. doi: 10.1038/labinvest. 2013.60

Cole, G. M., and Timiras, P. S. (1987). Ubiquitin-protein conjugates in Alzheimer's lesions. Neurosci. Lett. 79, 207-212. doi: 10.1016/0304-3940(87)90698-7

Cripps, D., Thomas, S. N., Jeng, Y., Yang, F., Davies, P., and Yang, A. J. (2006). Alzheimer disease-specific conformation of hyperphosphorylated paired helical filament-Tau is polyubiquitinated through Lys-48, Lys-11, and Lys-6 ubiquitin conjugation. J. Biol. Chem. 281, 10825-10838. doi: 10.1074/jbc.M512786200

Dauer, W., and Przedborski, S. (2003). Parkinson's disease: mechanisms and models. Neuron 39, 889-909. doi: 10.1016/S0896-6273(03)00568-3

Del Cano-Espinel, M., Acebes, J. R., Sanchez, D., and Ganfornina, M. D. (2015). Lazarillo-related Lipocalins confer long-term protection against type I Spinocerebellar Ataxia degeneration contributing to optimize selective autophagy. Mol. Neurodegener. 10:11. doi: 10.1186/s13024-015-0009-8

Del Prete, D., Rice, R. C., Rajadhyaksha, A. M., and D'adamio, L. (2016). Amyloid Precursor Protein (APP) May act as a substrate and a recognition unit for CRL4CRBN and Stub1 E3 ligases facilitating ubiquitination of proteins 
involved in presynaptic functions and neurodegeneration. J. Biol. Chem. 291, 17209-17227. doi: 10.1074/jbc.M116.733626

Dickey, C. A., Kamal, A., Lundgren, K., Klosak, N., Bailey, R. M., Dunmore, J., et al. (2007). The high-affinity HSP90-CHIP complex recognizes and selectively degrades phosphorylated tau client proteins. J. Clin. Investig. 117, 648-658. doi: $10.1172 /$ jci29715

Dickey, C. A., Yue, M., Lin, W. L., Dickson, D. W., Dunmore, J. H., Lee, W. C., et al. (2006). Deletion of the ubiquitin ligase CHIP leads to the accumulation, but not the aggregation, of both endogenous phospho- and caspase-3cleaved tau species. J. Neurosci. 26, 6985-6996. doi: 10.1523/jneurosci.074606.2006

Difiglia, M., Sapp, E., Chase, K. O., Davies, S. W., Bates, G. P., Vonsattel, J. P., et al. (1997). Aggregation of huntingtin in neuronal intranuclear inclusions and dystrophic neurites in brain. Science 277, 1990-1993. doi: 10.1126/science.277. 5334.1990

Doran, J. F., Jackson, P., Kynoch, P. A., and Thompson, R. J. (1983). Isolation of PGP 9.5, a new human neurone-specific protein detected by high-resolution two-dimensional electrophoresis. J. Neurochem. 40, 1542-1547. doi: 10.1111/j. 1471-4159.1983.tb08124.x

Durcan, T. M., Kontogiannea, M., Thorarinsdottir, T., Fallon, L., Williams, A. J., Djarmati, A., et al. (2011). The Machado-Joseph disease-associated mutant form of ataxin-3 regulates parkin ubiquitination and stability. Hum. Mol. Genet. 20, 141-154. doi: $10.1093 / \mathrm{hmg} / \mathrm{ddq} 452$

Evers, M. M., Schut, M. H., Pepers, B. A., Atalar, M., Van Belzen, M. J., Faull, R. L., et al. (2015). Making (anti-) sense out of huntingtin levels in Huntington disease. Mol. Neurodegener. 10:21. doi: 10.1186/s13024-015-0018-7

Fu, Y., Zhao, J., Atagi, Y., Nielsen, H. M., Liu, C. C., Zheng, H. H., et al. (2016). Apolipoprotein E lipoprotein particles inhibit amyloid-beta uptake through cell surface heparan sulphate proteoglycan. Mol. Neurodegener. 11:37. doi: 10.1186/ s13024-016-0099-y

Gautam, V., D’avanzo, C., Berezovska, O., Tanzi, R. E., and Kovacs, D. M. (2015). Synaptotagmins interact with APP and promote A beta generation. Mol. Neurodegener. 10:31. doi: 10.1186/s13024-015-0028-5

Geisler, S., Holmstrom, K. M., Skujat, D., Fiesel, F. C., Rothfuss, O. C., Kahle, P. J., et al. (2010). PINK1/Parkin-mediated mitophagy is dependent on VDAC1 and p62/SQSTM1. Nat. Cell Biol. 12, 119-131. doi: 10.1038/ncb2012

Goate, A., Chartier-Harlin, M. C., Mullan, M., Brown, J., Crawford, F., Fidani, L., et al. (1991). Segregation of a missense mutation in the amyloid precursor protein gene with familial Alzheimer's disease. Nature 349, 704-706. doi: 10. 1038/349704a0

Golovyashkina, N., Penazzi, L., Ballatore, C., Smith, A. B., Bakota, L., and Brandt, R. (2015). Region-specific dendritic simplification induced by A beta, mediated by tau via dysregulation of microtubule dynamics: a mechanistic distinct event from other neurodegenerative processes. Mol. Neurodegener. 10:60. doi: 10. 1186/s13024-015-0049-0

Gong, B., Cao, Z., Zheng, P., Vitolo, O. V., Liu, S., Staniszewski, A., et al. (2006). Ubiquitin hydrolase Uch-L1 rescues beta-amyloid-induced decreases in synaptic function and contextual memory. Cell 126, 775-788. doi: 10.1016/j.cell. 2006.06 .046

Grabbe, C., Husnjak, K., and Dikic, I. (2011). The spatial and temporal organization of ubiquitin networks. Nat. Rev. Mol. Cell Biol. 12, 295-307. doi: 10.1038/ nrm3099

Gu, Y., Jones, A. E., Yang, W., Liu, S. R., Dai, Q., Liu, Y. D., et al. (2016). The histone H2A deubiquitinase Usp16 regulates hematopoiesis and hematopoietic stem cell function. Proc. Natl. Acad. Sci. U.S.A. 113, E51-E60. doi: 10.1073/pnas. 1517041113

Han, D. H., Na, H. K., Choi, W. H., Lee, J. H., Kim, Y. K., Won, C., et al. (2014). Direct cellular delivery of human proteasomes to delay tau aggregation. Nat. Commun. 5:5633. doi: 10.1038/ncomms6633

Hardy, J., and Selkoe, D. J. (2002). The amyloid hypothesis of Alzheimer's disease: progress and problems on the road to therapeutics. Science 297, 353-356. doi: $10.1126 /$ science. 1072994

Hegde, A. N., Inokuchi, K., Pei, W., Casadio, A., Ghirardi, M., Chain, D. G., et al. (1997). Ubiquitin C-terminal hydrolase is an immediate-early gene essential for long-term facilitation in Aplysia. Cell 89, 115-126. doi: 10.1016/S0092-8674(00) 80188-9
Helferich, A. M., Ruf, W. P., Grozdanov, V., Freischmidt, A., Feiler, M. S., Zondler, L., et al. (2015). $\alpha$-synuclein interacts with SOD1 and promotes its oligomerization. Mol. Neurodegener. 10:66. doi: 10.1186/s13024-015-0062-3

Hong, X., Liu, J., Zhu, G., Zhuang, Y., Suo, H., Wang, P., et al. (2014). Parkin overexpression ameliorates hippocampal long-term potentiation and betaamyloid load in an Alzheimer's disease mouse model. Hum. Mol. Genet. 23, 1056-1072. doi: $10.1093 / \mathrm{hmg} / \mathrm{ddt} 501$

Hu, X., Shi, Q., Zhou, X., He, W., Yi, H., Yin, X., et al. (2007). Transgenic mice overexpressing reticulon 3 develop neuritic abnormalities. EMBO J. 26, 2755-2767. doi: 10.1038/sj.emboj.7601707

Hughes, A. J., Daniel, S. E., Kilford, L., and Lees, A. J. (1992). Accuracy Of ClinicalDiagnosis Of Idiopathic Parkinsons-Disease - A Clinicopathological Study Of 100 Cases. J. Neurol. Neurosur. Psychiatry 55, 181-184. doi: 10.1136/jnnp.55. 3.181

Huntington Study Group (1996). Unified huntington's disease rating scale: reliability and consistency. Mov. Disord. 11, 136-142. doi: 10.1002/mds. 870110204

Husnjak, K., Elsasser, S., Zhang, N., Chen, X., Randles, L., Shi, Y., et al. (2008). Proteasome subunit Rpn13 is a novel ubiquitin receptor. Nature 453, 481-488. doi: 10.1038/nature06926

Imai, Y., Soda, M., Hatakeyama, S., Akagi, T., Hashikawa, T., Nakayama, K., et al. (2002). CHIP is associated with Parkin, a gene responsible for familial Parkinson's disease, and enhances its ubiquitin ligase activity. Mol. Cell. 10, 55-67. doi: 10.1016/s1097-2765(02)00583-x

Jia, H., Kast, R. J., Steffan, J. S., and Thomas, E. A. (2012). Selective histone deacetylase (HDAC) inhibition imparts beneficial effects in Huntington's disease mice: implications for the ubiquitin-proteasomal and autophagy systems. Hum. Mol. Genet. 21, 5280-5293. doi: 10.1093/hmg/dds379

Joo, H. Y., Zhai, L., Yang, C., Nie, S., Erdjument-Bromage, H., Tempst, P., et al. (2007). Regulation of cell cycle progression and gene expression by H2A deubiquitination. Nature 449, 1068-1072. doi: 10.1038/nature06256

Kalia, L. V., Kalia, S. K., Chau, H., Lozano, A. M., Hyman, B. T., and Mclean, P. J. (2011). Ubiquitinylation of alpha-synuclein by Carboxyl Terminus Hsp70interacting protein (CHIP) is regulated by Bcl-2-associated athanogene 5 (BAG5). PLoS ONE 6:e14695. doi: 10.1371/journal.pone.0014695

Kaneko, M., Koike, H., Saito, R., Kitamura, Y., Okuma, Y., and Nomura, Y. (2010). Loss of HRD1-mediated protein degradation causes amyloid precursor protein accumulation and amyloid-beta generation. J. Neurosci. 30, 3924-3932. doi: 10.1523/jneurosci.2422-09.2010

Kawaguchi, Y., Okamoto, T., Taniwaki, M., Aizawa, M., Inoue, M., Katayama, S., et al. (1994). CAG expansions in a novel gene for Machado-Joseph disease at chromosome 14q32.1. Nat. Genet. 8, 221-228. doi: 10.1038/ng1194-221

Kitada, T., Asakawa, S., Hattori, N., Matsumine, H., Yamamura, Y., Minoshima, S., et al. (1998). Mutations in the parkin gene cause autosomal recessive juvenile parkinsonism. Nature 392, 605-608. doi: 10.1038/33416

Ko, H. S., Bailey, R., Smith, W. W., Liu, Z. H., Shin, J. H., Lee, Y. I., et al. (2009). CHIP regulates leucine-rich repeat kinase-2 ubiquitination, degradation, and toxicity. Proc. Natl. Acad. Sci. U.S.A. 106, 2897-2902. doi: 10.1073/pnas. 0810123106

Kulathu, Y., and Komander, D. (2012). Atypical ubiquitylation - the unexplored world of polyubiquitin beyond Lys48 and Lys63 linkages. Nat. Rev. Mol. Cell Biol. 13, 508-523. doi: 10.1038/nrm3394

Kumar, P., Ambasta, R. K., Veereshwarayya, V., Rosen, K. M., Kosik, K. S., Band, H., et al. (2007). CHIP and HSPs interact with beta-APP in a proteasomedependent manner and influence A beta metabolism. Hum. Mol. Genet. 16, 848-864. doi: $10.1093 / \mathrm{hmg} / \mathrm{ddm} 030$

Kuzuhara, S., Mori, H., Izumiyama, N., Yoshimura, M., and Ihara, Y. (1988). Lewy bodies are ubiquitinated. A light and electron microscopic immunocytochemical study. Acta Neuropathol. 75, 345-353. doi: 10.1007/ BF00687787

Lang, A. E., and Lozano, A. M. (1998). Parkinson's disease. First of two parts. New Engl. J. Med. 339, 1044-1053. doi: 10.1056/nejm199810083391506

Laplantine, E., Fontan, E., Chiaravalli, J., Lopez, T., Lakisic, G., Veron, M., et al. (2009). NEMO specifically recognizes K63-linked poly-ubiquitin chains through a new bipartite ubiquitin-binding domain. ЕMBO J. 28, 2885-2895. doi: 10.1038/emboj.2009.241 
Lee, B. H., Lee, M. J., Park, S., Oh, D. C., Elsasser, S., Chen, P. C., et al. (2010). Enhancement of proteasome activity by a small-molecule inhibitor of USP14. Nature 467, 179-184. doi: 10.1038/nature09299

Lee, M. J., Lee, B. H., Hanna, J., King, R. W., and Finley, D. (2011). Trimming of ubiquitin chains by proteasome-associated deubiquitinating enzymes. Mol. Cell. Proteomics 10, R110003871. doi: 10.1074/mcp.R110.003871

Leroy, E., Boyer, R., Auburger, G., Leube, B., Ulm, G., Mezey, E., et al. (1998). The ubiquitin pathway in Parkinson's disease. Nature 395, 451-452. doi: 10.1038/ 26652

Lesage, S., and Brice, A. (2009). Parkinson's disease: from monogenic forms to genetic susceptibility factors. Hum. Mol. Genet. 18, R48-R59. doi: 10.1093/hmg/ ddp012

Levy-Lahad, E., Wasco, W., Poorkaj, P., Romano, D. M., Oshima, J., Pettingell, W. H., et al. (1995). Candidate gene for the chromosome 1 familial Alzheimer's disease locus. Science 269, 973-977. doi: 10.1126/science.7638621

Liu, Y., Fallon, L., Lashuel, H. A., Liu, Z., Lansbury, P. T. Jr., et al. (2002). The UCH-L1 gene encodes two opposing enzymatic activities that affect alphasynuclein degradation and Parkinson's disease susceptibility. Cell 111, 209-218. doi: 10.1016/S0092-8674(02)01012-7

Lowe, J., Mcdermott, H., Landon, M., Mayer, R. J., and Wilkinson, K. D. (1990). Ubiquitin carboxyl-terminal hydrolase (PGP 9.5) is selectively present in ubiquitinated inclusion bodies characteristic of human neurodegenerative diseases. J. Pathol. 161, 153-160. doi: 10.1002/path.1711610210

Lu, X. H., Fleming, S. M., Meurers, B., Ackerson, L. C., Mortazavi, F., Lo, V., et al. (2009). Bacterial artificial chromosome transgenic mice expressing a truncated mutant parkin exhibit age-dependent hypokinetic motor deficits, dopaminergic neuron degeneration, and accumulation of proteinase K-resistant alphasynuclein. J. Neurosci. 29, 1962-1976. doi: 10.1523/jneurosci.5351-08.2009

MacDonald, M. E., Ambrose, C. M., Duyao, M. P., Myers, R. H., Lin, C., and Srinidhi, L. (1993). A novel gene containing a trinucleotide repeat that is expanded and unstable on Huntington's disease chromosomes, Huntington's Disease Collaborative Research Group. Cell 72, 971-983.

Majbour, N. K., Vaikath, N. N., Van Dijk, K. D., Ardah, M. T., Varghese, S., Vesterager, L. B., et al. (2016). Oligomeric and phosphorylated alpha-synuclein as potential CSF biomarkers for Parkinson's disease. Mol. Neurodegener. 11:7. doi: 10.1186/s13024-016-0072-9

Maraganore, D. M., Farrer, M. J., Hardy, J. A., Lincoln, S. J., Mcdonnell, S. K., and Rocca, W. A. (1999). Case-control study of the ubiquitin carboxy-terminal hydrolase L1 gene in Parkinson's disease. Neurology 53, 1858-1860. doi: 10. 1212/WNL.53.8.1858

Maraganore, D. M., Lesnick, T. G., Elbaz, A., Chartier-Harlin, M. C., Gasser, T., Kruger, R., et al. (2004). UCHL1 is a Parkinson's disease susceptibility gene. Ann. Neurol. 55, 512-521. doi: 10.1002/ana.20017

McNaught, K. S., and Jenner, P. (2001). Proteasomal function is impaired in substantia nigra in Parkinson's disease. Neurosci. Lett. 297, 191-194. doi: 10. 1016/S0304-3940(00)01701-8

Miller, V. M., Nelson, R. F., Gouvion, C. M., Williams, A., Rodriguez-Lebron, E., Harper, S. Q., et al. (2005). CHIP suppresses polyglutamine aggregation and toxicity in vitro and in vivo. J. Neurosci. 25, 9152-9161. doi: 10.1523/jneurosci. 3001-05.2005

Moore, D. J. (2006). Parkin: a multifaceted ubiquitin ligase. Biochem. Soc. Trans. 34, 749-753. doi: 10.1042/bst0340749

More, S. V., and Choi, D. K. (2015). Promising cannabinoid-based therapies for Parkinson's disease: motor symptoms to neuroprotection. Mol. Neurodegener. 10:17. doi: 10.1186/s13024-015-0012-0

Mori, H., Kondo, J., and Ihara, Y. (1987). Ubiquitin is a component of paired helical filaments in Alzheimer's disease. Science 235, 1641-1644. doi: 10.1126/science. 3029875

Morreale, F. E., and Walden, H. (2016). Types of Ubiquitin Ligases. Cell 165:e241. doi: 10.1016/j.cell.2016.03.003

Murata, H., Sakaguchi, M., Kataoka, K., and Huh, N. (2013). SARM1 and TRAF6 bind to and stabilize PINK1 on depolarized mitochondria. Mol. Biol. Cell 24, 2772-2784. doi: 10.1091/mbc.E13-01-0016

Myeku, N., Clelland, C. L., Emrani, S., Kukushkin, N. V., Yu, W. H., Goldberg, A. L., et al. (2016). Tau-driven $26 \mathrm{~S}$ proteasome impairment and cognitive dysfunction can be prevented early in disease by activating cAMP-PKA signaling. Nat. Med. 22, 46-53. doi: 10.1038/nm.4011
Nekrasov, E. D., Vigont, V. A., Klyushnikov, S. A., Lebedeva, O. S., Vassina, E. M., Bogomazova, A. N., et al. (2016). Manifestation of huntington's disease pathology in human induced pluripotent stem cell-derived neurons. Mol. Neurodegener. 11:27. doi: 10.1186/s13024-016-0092-5

Oh, S., Hong, H. S., Hwang, E., Sim, H. J., Lee, W., Shin, S. J., et al. (2005). Amyloid peptide attenuates the proteasome activity in neuronal cells. Mech. Ageing Dev. 126, 1292-1299. doi: 10.1016/j.mad.2005.07.006

Perry, G., Friedman, R., Shaw, G., and Chau, V. (1987). Ubiquitin is detected in neurofibrillary tangles and senile plaque neurites of Alzheimer disease brains. Proc. Natl. Acad. Sci. U.S.A. 84, 3033-3036. doi: 10.1073/pnas.84.9.3033

Petrucelli, L., Dickson, D., Kehoe, K., Taylor, J., Snyder, H., Grover, A., et al. (2004). CHIP and Hsp70 regulate tau ubiquitination, degradation and aggregation. Hum. Mol. Genet. 13, 703-714. doi: 10.1093/hmg/ddh083

Pickart, C. M. (2001). Mechanisms underlying ubiquitination. Annu. Rev. Biochem. 70, 503-533. doi: 10.1146/annurev.biochem.70.1.503

Polymeropoulos, M. H., Lavedan, C., Leroy, E., Ide, S. E., Dehejia, A., Dutra, A., et al. (1997). Mutation in the alpha-synuclein gene identified in families with Parkinson's disease. Science 276, 2045-2047. doi: 10.1126/science.276.5321.2045

Popovic, D., Vucic, D., and Dikic, I. (2014). Ubiquitination in disease pathogenesis and treatment. Nat. Med. 20, 1242-1253. doi: 10.1038/nm.3739

Popugaeva, E., Pchitskaya, E., Speshilova, A., Alexandrov, S., Zhang, H., Vlasova, O., et al. (2015). STIM2 protects hippocampal mushroom spines from amyloid synaptotoxicity. Mol. Neurodegener. 10:37. doi: 10.1186/s13024-0150034-7

Ravid, T., and Hochstrasser, M. (2008). Diversity of degradation signals in the ubiquitin-proteasome system. Nat. Rev. Mol. Cell Biol. 9, 679-690. doi: 10.1038/ nrm2468

Reyes-Turcu, F. E., Ventii, K. H., and Wilkinson, K. D. (2009). Regulation and cellular roles of ubiquitin-specific deubiquitinating enzymes. Annu. Rev. Biochem. 78, 363-397. doi: 10.1146/annurev.biochem.78.082307.091526

Rieser, E., Cordier, S. M., and Walczak, H. (2013). Linear ubiquitination: a newly discovered regulator of cell signalling. Trends Biochem. Sci. 38, 94-102. doi: 10.1016/j.tibs.2012.11.007

Rosen, K. M., Moussa, C. E., Lee, H. K., Kumar, P., Kitada, T., Qin, G., et al. (2010). Parkin reverses intracellular beta-amyloid accumulation and its negative effects on proteasome function. J. Neurosci. Res. 88, 167-178. doi: 10.1002/jnr.22178

Ross, C. A., Margolis, R. L., Rosenblatt, A., Ranen, N. G., Becher, M. W., and Aylward, E. (1997). Huntington disease and the related disorder, dentatorubralpallidoluysian atrophy (DRPLA). Medicine (Baltimore) 76, 305-338. doi: 10. 1097/00005792-199709000-00001

Rubinsztein, D. C. (2006). The roles of intracellular protein-degradation pathways in neurodegeneration. Nature 443, 780-786. doi: 10.1038/nature05291

Saha, S., Ash, P. E., Gowda, V., Liu, L., Shirihai, O., and Wolozin, B. (2015). Mutations in LRRK2 potentiate age-related impairment of autophagic flux. Mol. Neurodegener. 10:26. doi: 10.1186/s13024-015-0022-y

Sahara, N., Murayama, M., Mizoroki, T., Urushitani, M., Imai, Y., Takahashi, R., et al. (2005). In vivo evidence of CHIP up-regulation attenuating tau aggregation. J. Neurochem. 94, 1254-1263. doi: 10.1111/j.1471-4159.2005. 03272.x

Schonherr, C., Bien, J., Isbert, S., Wichert, R., Prox, J., Altmeppen, H., et al. (2016). Generation of aggregation prone N-terminally truncated amyloid beta peptides by meprin beta depends on the sequence specificity at the cleavage site. Mol. Neurodegener. 11:19. doi: 10.1186/s13024-016-0084-5

Selkoe, D. J. (2001). Alzheimer's disease: genes, proteins, and therapy. Physiol. Rev. $81,741-766$.

Setsuie, R., Wang, Y. L., Mochizuki, H., Osaka, H., Hayakawa, H., Ichihara, N., et al. (2007). Dopaminergic neuronal loss in transgenic mice expressing the Parkinson's disease-associated UCH-L1 I93M mutant. Neurochem. Int. 50, 119-129. doi: 10.1016/j.neuint.2006.07.015

Sharoar, M. G., Shi, Q., Ge, Y., He, W., Hu, X., Perry, G., et al. (2016). Dysfunctional tubular endoplasmic reticulum constitutes a pathological feature of Alzheimer's disease. Mol. Psychiatry 21, 1263-1271. doi: 10.1038/mp.2015.181

Sherrington, R., Rogaev, E. I., Liang, Y., Rogaeva, E. A., Levesque, G., Ikeda, M., et al. (1995). Cloning of a gene bearing missense mutations in early-onset familial Alzheimer's disease. Nature 375, 754-760. doi: 10.1038/375754a0

Shimura, H., Schlossmacher, M. G., Hattori, N., Frosch, M. P., Trockenbacher, A., Schneider, R., et al. (2001). Ubiquitination of a new form of alpha-synuclein 
by parkin from human brain: implications for Parkinson's disease. Science 293, 263-269. doi: 10.1126/science.1060627

Shimura, H., Schwartz, D., Gygi, S. P., and Kosik, K. S. (2004). CHIP-Hsc70 complex ubiquitinates phosphorylated tau and enhances cell survival. J. Biol. Chem. 279, 4869-4876. doi: 10.1074/jbc.M305838200

Song, L., Lu, S. X., Ouyang, X., Melchor, J., Lee, J., Terracina, G., et al. (2015). Analysis of tau post-translational modifications in rTg4510 mice, a model of tau pathology. Mol. Neurodegener. 10:14. doi: 10.1186/s13024-015-0011-1

Spratt, D. E., Walden, H., and Shaw, G. S. (2014). RBR E3 ubiquitin ligases: new structures, new insights, new questions. Biochem. J. 458, 421-437. doi: 10.1042/ bj20140006

Strittmatter, W. J., Saunders, A. M., Schmechel, D., Pericak-Vance, M., Enghild, J., Salvesen, G. S., et al. (1993). Apolipoprotein E: high-avidity binding to betaamyloid and increased frequency of type 4 allele in late-onset familial Alzheimer disease. Proc. Natl. Acad. Sci. U.S.A. 90, 1977-1981. doi: 10.1073/pnas.90.17. 8098

Tai, H. C., Serrano-Pozo, A., Hashimoto, T., Frosch, M. P., Spires-Jones, T. L., and Hyman, B. T. (2012). The synaptic accumulation of hyperphosphorylated tau oligomers in Alzheimer disease is associated with dysfunction of the ubiquitinproteasome system. Am. J. Pathol. 181, 1426-1435. doi: 10.1016/j.ajpath.2012. 06.033

Tallaksen-Greene, S. J., Ordway, J. M., Crouse, A. B., Jackson, W. S., Detloff, P. J., and Albin, R. L. (2003). Hprt(CAG)146 mice: age of onset of behavioral abnormalities, time course of neuronal intranuclear inclusion accumulation, neurotransmitter marker alterations, mitochondrial function markers, and susceptibility to 1-methyl-4-phenyl-1,2,3,6-tetrahydropyridine. J. Comp. Neurol. 465, 205-219. doi: 10.1002/cne.10855

Todi, S. V., and Paulson, H. L. (2011). Balancing act: deubiquitinating enzymes in the nervous system. Trends Neurosci. 34, 370-382. doi: 10.1016/j.tins.2011. 05.004

Vaden, J. H., Bhattacharyya, B. J., Chen, P. C., Watson, J. A., Marshall, A. G., Phillips, S. E., et al. (2015). Ubiquitin-specific protease 14 regulates c-Jun $\mathrm{N}$-terminal kinase signaling at the neuromuscular junction. Mol. Neurodegener. 10:3. doi: 10.1186/1750-1326-10-3

Valente, E. M., Abou-Sleiman, P. M., Caputo, V., Muqit, M. M. K., Harvey, K., Gispert, S., et al. (2004). Hereditary early-onset Parkinson's disease caused by mutations in PINK1. Science 304, 1158-1160. doi: 10.1126/science. 1096284

Valero, R., Marfany, G., Gonzalez-Angulo, O., Gonzalez-Gonzalez, G., Puelles, L., and Gonzalez-Duarte, R. (1999). USP25, a novel gene encoding a deubiquitinating enzyme, is located in the gene-poor region 21q11.2. Genomics 62, 395-405. doi: 10.1006/geno.1999.6025

Venkatraman, P., Wetzel, R., Tanaka, M., Nukina, N., and Goldberg, A. L. (2004). Eukaryotic proteasomes cannot digest polyglutamine sequences and release them during degradation of polyglutamine-containing proteins. Mol. Cell. 14, 95-104. doi: 10.1016/S1097-2765(04)00151-0

Warrick, J. M., Morabito, L. M., Bilen, J., Gordesky-Gold, B., Faust, L. Z., Paulson, H. L., et al. (2005). Ataxin-3 suppresses polyglutamine neurodegeneration in Drosophila by a ubiquitin-associated mechanism. Mol. Cell. 18, 37-48. doi: 10.1016/j.molcel.2005.02.030

Wilkinson, K. D., Lee, K. M., Deshpande, S., Duerksen-Hughes, P., Boss, J. M., and Pohl, J. (1989). The neuron-specific protein PGP 9.5 is a ubiquitin carboxylterminal hydrolase. Science 246, 670-673. doi: 10.1126/science. 2530630

Winborn, B. J., Travis, S. M., Todi, S. V., Scaglione, K. M., Xu, P., Williams, A. J., et al. (2008). The deubiquitinating enzyme ataxin-3, a polyglutamine disease protein, edits Lys63 linkages in mixed linkage ubiquitin chains. J. Biol. Chem. 283, 26436-26443. doi: 10.1074/jbc.M803692200
Wood, M. A., Kaplan, M. P., Brensinger, C. M., Guo, W., and Abel, T. (2005). Ubiquitin C-terminal hydrolase L3 (Uchl3) is involved in working memory. Hippocampus 15, 610-621. doi: 10.1002/hipo.20082

Xiang, W., Menges, S., Schlachetzki, J. C., Meixner, H., Hoffmann, A. C., Schlotzer-Schrehardt, U., et al. (2015). Posttranslational modification and mutation of histidine 50 trigger alpha synuclein aggregation and toxicity. Mol. Neurodegener. 10:8. doi: 10.1186/s13024-015-0004-0

Xiong, H., Wang, D., Chen, L., Choo, Y. S., Ma, H., Tang, C., et al. (2009). Parkin, PINK1, and DJ-1 form a ubiquitin E3 ligase complex promoting unfolded protein degradation. J. Clin. Invest. 119, 650-660. doi: 10.1172/jci 37617

Yamada, K., Patel, T. K., Hochgrafe, K., Mahan, T. E., Jiang, H., Stewart, F. R., et al. (2015). Analysis of in vivo turnover of tau in a mouse model of tauopathy. Mol. Neurodegener. 10:55. doi: 10.1186/s13024-015-0052-5

Yang, W., Lee, Y. H., Jones, A. E., Woolnough, J. L., Zhou, D. W., Dai, Q., et al. (2014). The histone H2A deubiquitinase Usp16 regulates embryonic stem cell gene expression and lineage commitment. Nat. Commun. 5:3818. doi: 10.1038/ ncomms 4818

Zempel, H., and Mandelkow, E. M. (2015). Tau missorting and spastininduced microtubule disruption in neurodegeneration: Alzheimer Disease and Hereditary Spastic Paraplegia. Mol. Neurodegener. 10:68. doi: 10.1186/s13024015-0064-1

Zhang, M., Deng, Y., Luo, Y., Zhang, S., Zou, H., Cai, F., et al. (2012). Control of BACE1 degradation and APP processing by ubiquitin carboxyl-terminal hydrolase L1. J. Neurochem. 120, 1129-1138. doi: 10.1111/j.1471-4159.2011. 07644.x

Zhang, Y. W., Thompson, R., Zhang, H., and Xu, H. (2011). APP processing in Alzheimer's disease. Mol. Brain 4:3. doi: 10.1186/1756-6606-4-3

Zhang, Z., Yang, H., and Wang, H. (2014). The histone H2A deubiquitinase USP16 interacts with HERC2 and fine-tunes cellular response to DNA damage. J. Biol. Chem. 289, 32883-32894. doi: 10.1074/jbc.M114.599605

Zhong, B., Liu, X., Wang, X., Chang, S. H., Liu, X., Wang, A., et al. (2012). Negative regulation of IL-17-mediated signaling and inflammation by the ubiquitin-specific protease USP25. Nat. Immunol. 13, 1110-1117. doi: 10.1038/ ni. 2427

Zimprich, A., Biskup, S., Leitner, P., Lichtner, P., Farrer, M., Lincoln, S., et al. (2004). Mutations in LRRK2 cause autosomal-dominant Parkinsonism with pleomorphic pathology. Neuron 44, 601-607. doi: 10.1016/j.neuron.2004. 11.005

Zoghbi, H. Y., and Orr, H. T. (2000). Glutamine repeats and neurodegeneration. Annu. Rev. Neurosci. 23, 217-247. doi: 10.1146/annurev.neuro.23.1.217

Zucchelli, S., Codrich, M., Marcuzzi, F., Pinto, M., Vilotti, S., Biagioli, M., et al. (2010). TRAF6 promotes atypical ubiquitination of mutant DJ-1 and alphasynuclein and is localized to Lewy bodies in sporadic Parkinson's disease brains. Hum. Mol. Genet. 19, 3759-3770. doi: 10.1093/hmg/ddq290

Conflict of Interest Statement: The authors declare that the research was conducted in the absence of any commercial or financial relationships that could be construed as a potential conflict of interest.

Copyright (c) 2016 Zheng, Huang, Zhang, Zhou, Luo, Xu and Wang. This is an open-access article distributed under the terms of the Creative Commons Attribution License (CC BY). The use, distribution or reproduction in other forums is permitted, provided the original author(s) or licensor are credited and that the original publication in this journal is cited, in accordance with accepted academic practice. No use, distribution or reproduction is permitted which does not comply with these terms. 